\title{
REKONSTRUKSI PEMERIKSAAN PERKARA DI PENGADILAN HUBUNGAN INDUSTRIAL BERBASIS NILAI CEPAT, ADIL DAN MURAH
}

\author{
Hono Sejati \\ Hakim Ad Hoc Pengadilan Hubungan Industrial di Pengadilan Negeri Yogyakarta \\ sejatihono@gmail.com
}

\begin{abstract}
Judge's decision should reflect the moral justice, social justice, and legal justice, the judge must hear the testimony of the parties, in order to produce a verdict worth of truth, honesty and has a value of fast, fair and cheap. In industrial disputes, the issue is how the dispute is resolved, in order to provide legal certainty based on values of justice for both workers and employers. Some issues examined in this study were (1) Why the Industrial Relations Court proceedings currently not fast, fair and cheap? (2) what barriers that happens in the proceedings in the Industrial Relations Court today that has not been fast, fair and cheap? (3) How is the reconstruction proceedings in the Industrial Relations Court based the value of fast, fair and cheap?

The research used sociological juridical approach. Data collection techniques were done by using interview, observation and documentation. Data were analyzed using interactive analysis method.

Results of this study conclude that (1) Examination of the Industrial Relations Court has yet fast, fair, and inexpensive. It is caused by differences in terms of filing a lawsuit in which the provisions of civil law. In the case of filing a lawsuit on his nervous at the district court in the area where the defendant place residence or domicile (Article 118 HIR / Article 142 RBg, whereas in Article 81 of Law No. 2 of 2004 stipulates that industrial relations disputes lawsuit in the District Court jurisdiction covers the workers / laborers. From these provisions, no factor sequititrum forum rei is known to be abandoned. Forming the Act does not provide an explanation of the application of the principle of a lawsuit filed in the workers / laborers. (2) The obstacles that occur in examinations litigation industrial relations are: filing a lawsuit, calling longer because the place stay defendant outside the jurisdiction of the courts located or the defendant has died, the company that has no operations or directors have left Indonesia, as well as the lack of control of the board Unions / Labour as the holder of the power which is actually not a graduate or undergraduate law will hinder the investigation because the process examination the judge must be active members of the advice and knowledge of proceedings. (3) Reconstruction of the court proceedings in industrial relations is based on the value of fast, fair, and inexpensive which is done by consensus as the settlement of disputes in the Industrial Relations Court.
\end{abstract}

Keywords: Industrial Relations Court, Value Fast, Fair and Cheap

\begin{abstract}
Abstrak
Putusan Hakim harus memcerminkan moral justice, social justice, dan legal justice, maka hakim harus mendengar keterangan para pihak, agar menghasilkan putusan bernilai kebenaran, kejujuran dan yang mempunyai nilai cepat, adil dan murah. Dalam perselisihan hubungan industrial, persoalannya adalah bagaimana perselisihan itu diselesaikan sehingga dapat memberikan kepastian hukum yang berbasis nilai keadilan bagi pekerja dan pengusaha. Permasalahan yang dikaji dalam penelitian ini adalah (1) Mengapa pemeriksaan perkara Pengadilan Hubungan Industrial saat ini belum cepat, adil dan murah? (2) Hambatan-hambatan apa saja yang terjadi
\end{abstract}


dalam pemeriksaan perkara di Pengadilan Hubungan Industrial saat ini yangbelum cepat, adil dan murah? (3) Bagaimana rekonstruksi pemeriksaan perkara di Pengadilan Hubungan Industrial yang berbasis nilai cepat, adil dan murah?

Metode penelitian menggunakan pendekatan yuridis sosiologis. Teknik pengumpulan data dengan wawancara, observasi, dan dokumentasi. Teknik analisis data menggunakan metode analisis interaktif. Hasil penelitian ini menyimpulkan, bahwa (1) Pemeriksaan perkara di Pengadilan Hubungan Industrial saat ini belum cepat, adil, dan murah disebabkan terutama oleh perbedaan dalam hal pengajuan gugatan dimana pada ketentuan hukum acara perdata dalam hal pengajuan gugatan pada asasnya di pengadilan negeri di wilayah mana tergugat bertemat tinggal atau berdomisili (Pasal $118 \mathrm{HIR} /$ Pasal $142 \mathrm{RBg}$, sedangkan pada Pasal $81 \mathrm{UU}$ No. 2 Tahun 2004 mengatur bahwa gugatan perselisihan hubungan industrial pada Pengadilan Negeri yang daerah hukumnya meliputi tempat pekerja/buruh bekerja. Dari ketentuan tersebut ada factor sequititrum forum rei yang selama ini dikenal ditinggalkan. Pembentuk Undangundang tidak memberikan penjelasan tentang diterapkannya asas gugatan diajukan di tempat pekerja/buruh bekerja. (2) Hambatan-hambatan yang terjadi dalam pemeriksaaan perkara pengadilan hubungan industrial adalah : pengajuan gugatan, pemanggilan yang lebih lama karena tempat tinggal tergugat di luar wilayah hukum PHI berada atau pihak tergugat sudah meninggal dunia, perusahaan yang sudah tidak operasional atau direkturnya telah meninggalkan Indonesia, serta kurangnya penguasaan pengurus Serikat Pekerja/Buruh sebagai pemegang kuasa yang notabene bukan sarjana atau sarjana hokum akan menghambat pemeriksaan karena dalam proses pemeriksaan hakim harus aktif member saran dan pengetahuan beracara. (3) Rekonstruksi pemeriksaan perkara di pengadilan hubungan industrial yang berbasis nilai cepat, adil, dan murah adalah dengan cara musyawarah mufakat sebagai penyelesaian perselisihan di Pengadilan Hubungan Industrial.

\section{Kata Kunci : Pengadilan Hubungan Industrial, Nilai Cepat, Adil dan Murah.}

\section{A. Pendahuluan}

Saat ini hukum acara perselisihan hubungan industrial yang berlaku dirasakan tidak mampu menampung dinamika praktik peradilan perdata. Ada kondisi antagonisme dalam praktik hukum. Di satu sisi, era Reformasi hukum menghendaki institusi peradilan sebagai salah satu pilar penegakan hukum dan keadilan dalam menjalankan tugas pokok harus merujuk pada produk hukum hasil reformasi, di sisi lain aturan beracara dalam praktik di pengadilan malah mengacu pada hukum warisan kolonial. Kita memang sudah merdeka tetapi merdeka dengan hukum asing.

Kebutuhan akan hukum perselisihan hubungan industrial nasional memang sangat mendesak dan perlu penyesuaian dengan kebijakan politik hukum, memperkuat peran lembaga peradilan sebagai salah satu pilar penegakan hukum dalam pembangunan hukum nasional. Jadi menata kembali regulasi yang berkaitan dengan penyelenggaraan praktik peradilan guna mewujudkan pelaksanaan tugas pokok dan fungsi lembaga peradilan secara optimal. Hal ini sejalan agenda reformasi hukum yang intinya menghendaki berbagai pembenahan di lingkungan pengadilan, seperti sumber daya manusia, administrasi pengadilan, dan infrastruktur termasuk hukum acaranya. Kita tidak bisa terus-menerus memakai hukum acara warisan kolonial yang sudah usang seperti HIR/ $\mathrm{RBg}$. Selain usang, hukum acara perdata itu bersifat dualisme, HIR berlaku untuk wilayah Jawa dan Madura sedangkan RBg berlaku di luar Jawa, meski isinya tidak jauh berbeda. ${ }^{1}$

Direktorat Jenderal Perundang-undangan, Kementerian Hukum dan HAM, telah menyusun Rancangan UU Hukum Acara Perdata (RUUHAP), namun rancangan yang disusun tahun 2006 itu masih memerlukan penyempurnaan. ${ }^{2}$

1 Varia Peradilan No. 302 Januari 2011

2 Lihat Rancangan Undang-Undang Hukum Acara Perdata, disusun oleh Direktorat Jenderal Perundangan Departemen Hukum dan HAM-RI, Tahun 2006. 
Pengaturan tentang prosedur atau tata cara sidang belum tercermin dalam RUU itu. Mungkin materi RUU itu perlu lebih disosialisasikan lagi di lingkungan pengadilan sebagai institusi pemakai UU itu kelak, sehingga diharapkan implementasi UU itu akan lebih baik.

Dalam mewujudkan tujuan peradilan yang sederhana, cepat, dan biaya ringan, ${ }^{3}$ maka Mahkamah Agung sebagai penyelenggara peradilan tertinggi di Indonesia mulai menggagas beberapa metode untuk mempersingkat proses penyelesaian perselisihan di pengadilan, namun dapat memberikan hasil yang lebih optimal. Salah satu gagasan yang cukup progresif antara lain dengan mengoptimalkan lembaga mediasi pada perkara-perkara perdata. Hal mana dimaksudkan agar para pihak yang beperkara tidak harus menempuh seluruh tahapan proses persidangan yang panjang dan memakan waktu lama, namun cukup hanya sampai pada tahap pra pemeriksaan saja, jika para pihak berhasil mencapai kesepakatan perdamaian melalui mediasi di awal persidangan.

Dalam proses mediasi para pihak akan difasilitasi oleh seorang mediator yang dapat dipilih dari dalam atau dari luar pengadilan yang memiliki independensi terhadap materi perkara dan keterikatan dengan para pihak yang berselisih. Mediator selain akan mempelajari materi perkara, juga dapat melakukan pendalaman secara personal melalui kaukus atau pertemuan secara intensif dengan salah satu pihak yang tidak mungkin dilakukan oleh hakim yang menyidangkan perkaranya. Di sinilah salah satu letak kelebihan proses perdamaian dengan bantuan seorang mediator dibandingkan dengan perdamaian yang difasilitasi oleh hakim yang menyidangkan perkaranya.

Fenomena tentang perselisihan hubungan industrial yang melibatkan antara pihak pekerja dan pengusaha yang ditentukan dalam persidangan hubungan industrial dengan difasilitasi hakim karir dan hakim ad-hoc dari unsur pekerja dan unsur pengusaha sampai saat ini belum cepat, adil, dan murah sehingga perlu dilakukan rekonstruksi.

3 R. Setiawan, 1992, Aneka Masalah Hukum dart Hukum Acara Perdata, Alumni, Bandung, hIm. 426, Lihat juga Pasal 2 Ayat (4) Undang-Undang Nomor 48 Tahun 2009 tentang Kekuasaan Kehakiman.
Rekonstruksi dilakukan terhadap prosedur yang berlaku dalam pemeriksaan perkara hubungan industrial khususnya di Pengadilan Hubungan Industrial pada Pengadilan Negeri Yogyakarta.

Berdasarkan uraian di atas, maka dapat dirumuskan permasalahan dalam penelitian ini, sebagai berikut:

1. Bagaimana pelaksanaan pemeriksaan perkara di Pengadilan Hubungan Industrial saat ini?

2. Hambatan-hambatan apa saja yang terjadi dalam pemeriksaan perkara di Pengadilan Hubungan Industrial saat ini?

3. Bagaimana rekonstruksi pemeriksaan perkara di Pengadilan Hubungan Industrial yang berbasis nilai cepat, adil dan murah?

\section{B. Metode Penelitian}

Paradigma yang penulis gunakan pada penelitian ini adalah paradigma Constructivism atau Legal Constructivism ${ }^{4}$ yaitu teori yang menyatakan bahwa individu menginterpretasikan dan beraksi menurut kategori konseptual dari pikiran. Realitas tidak menggambarkan diri individu namun harus disaring melalui cara pandang orang terhadap realitas tersebut. Teori konstruktivisme dibangun berdasarkan teori yang ada sebelumnya, yaitu konstruksi pribadi atau konstruksi personal (personal construct) oleh George Kelly.

Metode pendekatan penelitian yang penulis pergunakan adalah metode penelitian hukum yuridis sosiologis. Metode penelitian hukum sosiologis (yuridis sosiologis) adalah metode penelitian hukum empiris, yaitu penelitian yang mengacu pada observasi, wawancara dan pengambilan contoh nyata (sample) sebagai data empiris. ${ }^{5}$ Penelitian ini merupakan pendekatan yuridis-empiris. Pendekatan yuridis, digunakan untuk menganalisis berbagai peraturan perundangundangan terkait dengan Pemeriksaan Perkara

4 Guba dan Lincoln, 1994, Computing Paradigms in Qualitative Research, dalam Handbook of Qualitative Research, London, Sage Publikation, hlm. 105. Lihat dalam Norman K. Denzin, Yvonna S. Lincoln, 2009, Handbook of Qualitative Research, terjemah Dariyatno, dkk, Pustaka Pelajar, Yogyakarta, hlm. 124.

5 Ronny Hannitijo Soemitro, Op. Cit., hlm. 98. 
Putusan Pengadilan Hubungan Industrial dalam Undang-Undang Nomor 2 Tahun 2004 tentang Pengadilan Hubungan Industrial. Pendekatan empiris, digunakan untuk menganalisis hukum yang dilihat sebagai prilaku masyarakat yang berpola dalam kehidupan masyarakat yang selalu berinteraksi dan berhubungan dalam aspek kemasyarakatan. ${ }^{6}$ Metode penelitian hukum sosiologis (yuridis sosiologis) adalah untuk memperoleh keterangan dan penjelasan tentang hal-hal yang berkenaan dengan berbagai faktor yang berkaitan dengan permasalahan pemeriksaan perkara putusan Pengadilan Hubungan Industrial dalam Undang-Undang Nomor 2 Tahun 2004 tentang Pengadilan Hubungan Industrial.

Lokasi penelitian yang dipilih oleh penulis adalah di Pengadilan Hubungan Industrial pada Pengadilan Negeri Yogyakarta. Spesifikasi penelitian dalam studi ini adalah penelitian deskriptif analistis. ${ }^{7}$ Tujuan dari penelitian deskriptif adalah untuk mempertegas hipotesis-hipotesis yang pada arnya dapat membantu dalam pembentukan teori baru atau memperkuat teori lama. ${ }^{8}$

Penelitian ini berupaya untuk mendeskripsikan dan menganalisis tentang pemeriksaan perkara putusan pengadilan hubungan industrial. Hal tersebut kemudian dibahas atau dianalisis menurut ilmu dan teori-teori atau pendapat peneliti sendiri, dan terakhirr menyimpulkannya.

Dalam penelitian pada umumnya dibedakan antara data yang diperoleh secara langsung dari subjek/ informan penelitian dan dari bahanbahan pustaka. Data yang diperoleh secara langsung dinamakan data primer, sedangkan data yang diperoleh dari bahan-bahan pustaka lazimnya dinamakan data sekunder. Data primer adalah data yang diperoleh langsung dari masyarakat. ${ }^{9}$ Data primer diperoleh dari

6 Bambang Sunggono, 2003, Metodologi Penelitian Hukum, Raja Grafindo Persada, Jakarta, hlm. 43.

7 Menurut Kamus Besar Bahasa Indonesia, "analitis" (analisistis) artinya adalah bersifat analisis. Sedangkan arti analisis di antaranya adalah "proses pemecahan masalah yang dimulai dengan dugaan akan kebenarannya".

8 Koentjaraningrat, 1997, Metode-Metode Penelitian Masyarakat, Gramedia Pustaka Utama, Jakarta, hlm. 29-32.

9 Loc. cit wawancara dengan 4 (empat) hakim, 2 (dua) mediator, 2 (dua) pengacara, dan 2 (dua) informan dari para pihak yang berperkara. Data sekunder mencakup bahan hukum primer, bahan hukum sekunder, dan bahan hukum tertier.

Dalam penelitian ini untuk menggunakan data primer dan data sekunder yang diperoleh melalui: Studi Kepustakaan, yaitu pengumpulan dan mengkaji data sekunder. Data sekunder mencakup bahan hukum primer, bahan hukum sekunder, dan bahan hukum tertier. ${ }^{10}$ Data sekunder yang penulis gunakan dalam penelitian ini adalah terdiri atas :

1) Bahan hukum primer, yakni bahan-bahan hukum yang mengikat seperti:

- Al-Quran dan As-Sunnah

- Undang-Undang Dasar Negara RI Tahun 1945

- Undang-Undang Nomor 13 Tahun 2003 tentang Ketenagakerjaan.

- Undang-Undang Nomor 2 Tahun 2004 tentang Penyelesaian Perselisihan Hubungan Industrial.

- Kitab Undang-Undang Hukum Perdata (BW)

- Putusan Pengadilan Negeri dan putusan Mahkamah Agung RI yang telah berkekuatan hukum tetap.

2) Bahan-bahan hukum sekunder, yakni bahan-bahan yang erat hubungannya dengan bahan hukum primer dan dapat membantu menganalisis dan memahami bahan hukum primer ${ }^{11}$ seperti Tafsir AlQuran, Al-Hadits, kitab-kitab Fiqih, bukubuku, hasil penelitian, jurnal ilmiah, jurnal hukum, majalah hukum, artikel ilmiah, SEMA, PERMA dan makalah hasil seminar yang terkait dengan materi penelitian.

3) Bahan hukum tertier, yakni bahan-bahan yang memberikan informasi tentang bahan-bahan hukum primer dan bahan hukum sekunder, ${ }^{12}$ berupa kamus-kamus seperti kamus bahasa Indonesia, kamus bahasa Inggris dan kamus bahasa Arab serta kamus-kamus keilmuan seperti kamus hukum.

10 Ibid., hlm. 13.

11 Ronny Hanitijo Soemitro, 1994, Op. Cit, hlm. 10.

12 Loc.cit. 
C. Hasil Penelitian dan Pembahasan

1. Pelaksanaan pemeriksaan perkara di Pengadilan Hubungan Industrial.

Dengan adanya temuan disertasi atau rekonstruksi pemeriksaan perkara di pengadilan hubungan industrial ini, maka terjadi musyawarah mufakat antara pekerja dan pengusaha yang mengakibatkan terjadinya harmonisasi di tingkat pengadilan hubungan industrial yang mendukung Teori keadilan/ musyawarah mufakat, Teori Responsif, Teori Penegakan hukum, Teori Konflik, dan Teori Hukum Progresif.

Konsep pemeriksaan perkara di Pengadilan Hubungan Industrial melibatkan 4 unsur pendukung yaitu pekerja, LSM ketenagakerjaan, pengusaha dan pemerintah. Keempat aspek ini paling terkait dalam melaksanakan pengadilan di hubungan industrial melalui serikat pekerja. Dari keempat unsur tersebut pekerja, pengusaha dan pemerintah merupakan unsur yang dianggap memiliki posisi strategis sebagai faktor kunci yang menghubungkan atau memiliki korelasi antara pengusaha dan pekerja yang rentan dengan konflik.

Sebagai konsep yang dimanfaatkan dalam menganalisis kepentingan hukum berperspektif keadilan, maka dipergunakan hukum progresif, mengingat bahwa dinamika hukum tidak kunjung berhenti, oleh karena hukum terus menerus berada pada status membangun diri, dengan demikian terjadinya perubahan sosial dengan didukung oleh social engineering by law yang terencana akan mewujudkan apa yang menjadi tujuan hukum progresif yaitu untuk mencapai kesejahteraan dan kebahagiaan umat manusia. Untuk itu, pengadilan hubungan industrial yang berbasis nilai cepat, adil, dan murah harus dibangun secara konstruktif bagi pekerja maupun serikat pekerja yang mampu menciptakan hubungan industrial damai, dan untuk menciptakan kesejahteraan pekerja beserta keluarganya perlu didasarkan pada pola pikir hukum yang progresif yang sangat berbeda dengan paradigma hukum positivistik.
Konstruksi dilakukan dengan menganalisis pemeriksaan perkara dalam hubungan industrial, beserta hambatan-hambatan yang menyertainya melalui penafsiran realitas hukum baik menyangkut perilaku maupun teks pengaturan yang terkait dengan nilainilai keadilan serta fungsi negara dalam mewujudkan kesejahteraan Indonesia dan konstruksi-konstruksi tentang penyelesaian perselsihan hubungan industrial, pada tiga domain yang berbeda, yang meliputi domain pembuat undang-undang (rules making institutions), domain masyarakat atau pemegang peran (role occupant), dan domain penegakanhukum (rulessanctioninstitutions). ${ }^{13}$ Konstruksi yang dibangun berdasarkan basis keadilan manakah yang bisa diterapkan oleh negara dalam pelaksanaan pemeriksaan perkara di pengadilan hubungan industrial yang berbasis nilai cepat, adil, dan murah adalah untuk memberikan keadilan yang sebesar-besarnya bagi rakyat (pekerja dan pengusaha), dan dengan hukum keadilan itu harus diwujudkan oleh Negara.

Berdasarkan hasil penelitian dan temuan disertasi rekonstruksi pemeriksaan perkara di pengadilan hubungan industrial ini, maka teori baru yang dihasilkan merupakan pengembangan dari teori musyawarah mufakat antara pekerja dan pengusaha yang mengakibatkan terjadinya harmonisasi di tingkat pengadilan hubungan industrial.

Menurut budaya masyarakat di Indonesia musyawarah/mufakat merupakan metode penyelesaian sengketa yang sangat efektif dan lebih efisiendibandingkan dengan penyelesaian melalui pengadilan. Metode ini sebenarnyasudah dikenal jauh sebelum Indonesia merdeka. Dalam hubungan industrial,penyelesaian sengketa melalui musyawarah dapat menghindari konflik di bidang ketenagakerjaan atau minimal intensitasnya dapat dikurangi. Apabila terjadi konflik maka penyelesaian perselisihan dapat diupayakan secara damai dengantidak

13 Von Schimd I, dalam Gunarto, 2011. Rekonstruksi Konsep Kebebasan Berserikat Melalui Serikat Pekerja pada Hubungan Industrial Berbasis Nilai Keadilan Menuju Kesejahteraan Pekerja. Ringkasan Disertasi hlm. 11. 
menutup kemungkinan mekanisme paksaan. ${ }^{14}$ Hal ini dapat dilihat dalamUndang-Undang No. 2 Tahun 2004 tentang Penyelesaian Perselisihan Hubunganlndustrial, yang menegaskan bahwa para pihak wajib mengupayakan penyelesaian perselisihan melalui jalan perundingan bipartit sebelum melakukan upaya lain. ${ }^{15}$

Sehubungan dengan otonomi daerah dewasa ini yang berdasarkan Pasal 14 ayat (1) huruf h Undang-undang No. 32 Tahun 2004, disebutkan bahwa urusan yang menjadi kewenangan Pemerintahan Daerah untuk Kabupaten dan Kota merupakan urusan yang berskala Kabupaten/Kota meliputipelayanan bidang ketenagakerjaan. ${ }^{16}$ Pengaturan tenaga kerja di daerah harus disesuaikan dengan standar Hukum Nasional dan Hukum Internasional yang sesuai dengan asas negara demokrasi. Begitu juga dalam hal penyelesaian perselisihan hubungan industrial khususnya masalah PHK, apabila diselesaikan melalui mediasi maka mediatornyayang berada pada Dinas Tenaga Kerja dan Transmigrasi yang ada di daerah tempat PHK terjadi serta harus dapat disesuaikan dengan kondisi daerah dan para pelaku usaha yang ada di Kabupaten/Kota. Dalam upaya menyelesaikan perselisihan ini juga harus memperhatikan Hukum Nasional dan Hukum Internasional yang berlaku.

Bentuk penyelesaian sengketa yang pertama dan paling penting adalah Negosiasi (negosiation). Pengendalian semacam ini terwujud melalui lembaga-lembaga tertentu yang memungkinkan timbulnya pola diskusi atau negosiasi dalam pengambilan keputusan di antara para pihak yang berlawanan terhadap persoalan-persoalan yang mereka pertentangkan.

14 Aloysius Uwiyono, Implikasi Hukum Pasar Bebas dalam Kerangka AFTA terhadap Hukum Ketenagakerjaan di Indonesia. Jurnal Hukum Bisnis, Vol. 22, Yayasan Pengembang Hukum Bisnis, Jakarta, 2003, hlm. 41.

15 Pasal 3 ayat (1) Undang-undang Nomor 2 Tahun 2004

16 Pasal 14 ayat (1) ayat (1) huruf h Undang-undang No. 32 Tahun 2004 tentang Pemerintahan Daerah.
Di dalam mediasi kedua belah pihak yang bertentangan menyetujui untuk menerima pihak ketiga menyelesaikan sengketanya. Tetapi mereka bebas untumenerima atau menolak keputusan tersebut. Melalui mekanisme pengendalian sengketa yang efektif akan menjadikan suatu kondisi yang kondusif, dengan katalain dalam mediasi kekuasaan tertinggi ada di para pihak masingmasing yang bersengketa. Mediator sebagai pihak ketiga yang dianggap netral hanya membantuatau memfasilitasi jalannya proses mediasi saja. Sebagaimana diungkapkan oleh Karl A. Slaikeu, bahwa:"Mediation is a process through which a third party helps two or moreother parties achieve their own resolution on one or more issues"17 Proses mediasi menghasilkan suatu kesepakatan antara para pihak (mutually acceptable solution). Kesepakatan para pihak ini lebih kuat sifatnya dibandingkan putusan pengadilan, karena merupakan hasil dari kesepakatan para pihak yang bersengketa. Artinya kesepakatan itu adalah hasil kompromi atau jalan tengah yangtelah mereka pilih untuk disepakati demi kepentingan-kepentingan mereka bersama. Sedangkan dalam putusan pengadilan ada pihak lain yang memutuskan, yaitu hakim. Putusan pengadilan itu bukan hasil kesepakatan para pihak, melainkan lebih dekat pada perasaan keadilan hakim itu sendiri yang belum tentu sama dengan perasaan keadilan dari para pihak yang bersengketa.

\section{Hambatan-hambatan yang terjadi dalam pemeriksaan perkara di Pengadilan Hubungan Industrial.}

Hambatan-hambatan yang terjadi dalam pemeriksaaan perkara pengadilan hubungan industrial adalah hambatan substantif dan hambatan procedural yaitu berkenaan dengan pemeriksaan perkara yang mebutuhkan waktu selambat-lambatnya 3 (tiga) hari kerja sejak penetapan majelis hakim, maka ketua majelis hakim haruslah sudah melakukan sidang pertama melalui

17 Karl A Slaikeu, When Push Comes to Shove: A Practical Strategies for Resolving Disputes, San Fransisco, Jossey-Bass, Inc. 1996, hlm. 3 
pemanggilan satu dengan media SMS, whatssapp, atau email, dan tidak harus menggunakan relaas panggilan.

3. Rekonstruksi pemeriksaan perkara di Pengadilan Hubungan Industrial yang berbasis nilai cepat, adil dan murah.

Untuk mengatasi hambatan subtansial mmaka dilakukan rekonstruksi Pasal 103 UU no.2 Tahun 2004 isinya majelis hakim wajb memberikan putusan penyelesaian $\mathrm{PHI}$ dalam waktu selambat-lambatnya 30 (tiga puluh) hari terhitung sejak sidang pertama dengan ditambahkan mempersingkat menjadi 4 (empat) persidangan:

(1) perdamaian penggugat dan tergugat oleh hakim

(2) Pembacaan gugatan dan jawab jinawab

(3) Pembuktian penggugat dan tergugat

(4) Putusan

Untuk membangun konsep pemeriksaan perkara di pengadilan hubungan industrial harus menyesuaikan juga dengan budaya masyarakat di Indonesia dimana musyawarah/ mufakat sehingga musyawarah berkeadilan merupakan metode penyelesaian sengketa yang sangat efektif dan lebih efisien dibandingkan dengan penyelesaian melalui pengadilan. Metode ini sebenarnya sudah dikenal jauh sebelum Indonesia merdeka. Dalam hubungan industrial, penyelesaian sengketa melalui musyawarah dapat menghindari konflik di bidang ketenagakerjaan atau minimal intensitasnya dapat dikurangi. Apabila terjadi konflik maka penyelesaian perselisihan dapat diupayakan secara damai dengan tidak menutup kemungkinan mekanisme paksaan. ${ }^{18} \mathrm{Hal}$ ini dapat dilihat dalam Undang-Undang No. 2 Tahun 2004 tentang Penyelesaian Perselisihan Hubunganlndustrial, yang menegaskan bahwa para pihak wajib mengupayakan penyelesaian perselisihan melalui jalan perundingan bipartit sebelum melakukan upaya lain. Jadi musyawarah berkeadilan merupakan teori baru yang dibangun dari penelitian disertasi ini.

\section{Penutup}

\section{Simpulan}

Berdasarkan uraian yang telah dipaparkan dalam bab-bab sebelumnya, maka dapat dirumuskan beberapa kesimpulan sebagai jawaban atas tiga permasalahan penelitian, yaitu sebagai berikut :

1. Pemeriksaan perkara di Pengadilan Hubungan Industrial saat ini belum cepat, adil, dan murah disebabkan terutama oleh perbedaan dalam hal pengajuan gugatan dimana pada ketentuan hukum acara perdata dalam hal pengajuan gugatan pada dasarnya di pengadilan negeri di wilayah mana tergugat bertempat tinggal atau berdomisili (Pasal 118 HIR/Pasal 142 RBg, sedangkan pada Pasal 81 UU No. 2 Tahun 2004 mengatur bahwa gugatan perselisihan hubungan industrial pada Pengadilan Negeri yang daerah hukumnya meliputi tempat pekerja/buruh bekerja. Dari ketentuan tersebut ada factor sequititrum forum rei yang selama ini dikenal ditinggalkan. Pembentuk Undang-undang tidak memberikan penjelasan tentang diterapkannya asas gugatan diajukan di tempat pekerja/buruh bekerja.

2. Hambatan-hambatan yang terjadi dalam pemeriksaaan perkara pengadilan hubungan industrial adalah : pengajuan gugatan, pemanggilan yang lebih lama karena tempat tinggal tergugat di luar wilayah hukum $\mathrm{PHI}$ berada atau pihak tergugat sudah meninggal dunia, perusahaan yang sudah tidak operasional atau direkturnya telah meninggalkan Indonesia, serta kurangnya penguasaan pengurus Serikat Pekerja/Buruh sebagai pemegang kuasa yang notabene bukan sarjana atau sarjana hukum akan menghambat pemeriksaan karena dalam proses pemeriksaan hakim harus aktif memberi saran dan pengetahuan beracara. 
3. Rekonstruksi nilai ideal pemeriksaaan perkara di PHI yang adil, cepat, dan murah bertujuan untuk mengembalikan harmonisasi hubungan buruh dengan pengusaha melalui musyawarah mufakat di sidang perdamaian PHI. Adapun rekonstruksi hukum terhadap pemeriksaan perkara di PHI yang cepat, adil, dan murah adalah : Pasal 89 ayat 1 UU No 2 Tahun 2004 yang isinya dalam waktu selambat-lambatnya 3 (tiga) hari kerja sejak penetapan majelis hakim, maka ketua majelis hakim haruslah sudah melakukan sidang pertama melalui pemanggilan satu dengan media SMS, whatssapp, atau email, dan tidak harus menggunakan relaas panggilan.

Rekonstruksi Pasal 103 UU no.2 Tahun 2004 tentang PPHI isinya majelis hakim wajb memberikan putusan penyelesaian $\mathrm{PHI}$ dalam waktu selambat-lambatnya 30 (tiga puluh) hari terhitung sejak sidang pertama dengan ditambahkan mempersingkat menjadi 4 (empat) persidangan :

(1) Perdamaian penggugat dan tergugat oleh hakim

(2) Pembacaan gugatan dan jawab jinawab

(3) Pembuktian penggugat dan tergugat

(4) Putusan

Implikasi teoretis kajian adalah bahwa perubahan paradigma pemeriksaan perkara putusan yang berbasis adil, cepat dan murah yang menghasilkan putusan mengembalikan harmonisasi antara buruh dan pengusaha akan berimplikasi kepada beberapa aspek, secara umum keadilan diartikan sebagai perbuatan atau perlakuan yang adil. Sementara adalah adil adalah tidak berat sebelah. Keadian menurut kajian filsafat adalah apabila dipenuhi dua prinsip, yang pertama tidak merugikan seseorang dan kedua, perlakuan kepada tiaptiap manusia apa yang menjadi haknya, jika kedua prinsip ini dapat dipenuhi barulah itu dikatakan adil dalam konteks perselisihan hubungan industrial para pihak yang berpekara terjalin adanya harmonisasi.

Pada prakteknya, pemahaman keadilan dalam penanganan penyelesaian pemeriksaan perkara putusan di Pengadilan Hubungan Industrial masih debatable. Banyak pihak menilai lembaga pengadilan kurang adil, karena terlalu sarat dengan prosedural, formalistis, kaku dan belum terwujud yang didambakan para pihak yaitu yang mempunyai nilai cepat, adil dan murah. Faktor tersebut tidak terlepas dari cara pandang Hakim terhadap hukum yang penerapannya masih normatif prosedural yang seharusnya hakim mampu menangkap semangat keadilan dalam pihak pekerja/ pengusaha yang masih terpengaruh hukum yang normatif prosedural. Hakim dituntut mempunyai keberanian mengambil keputusan yang berbeda dengan ketentuan normatif undang-undang, sehingga pemeriksaan perkara putusan di Pengadilan Hubungan Industrial yang cepat, adil dan murah bisa dirasakan oleh para pihak pencari keadilan sehingga tercipta kembali harmonisasi hubungan pekerja dan pengusaha.

Implikasi praktisnya bahwa waktu pemanggilan (relaas) lebih cepat karena melalui media komunikasi terkini seperti sms, whatsapp, dan email tidak harus menggunakan relaas panggilan. Terjadi harmonisasi diantara pekerja dan pengusaha karena hakim aktif/tidak pasif untuk mengupayakan terjadinya perdamaian.

\section{Saran}

Saran-saran yang diajukan adalah:

a. Untuk lebih berfungsinya lembaga pengadilan hubungan industrial dalam melayani para pencari keadilan perlu meningkatkan kualiats sumberdaya manusia kepada para pelaksananya dalam proses perselisihan, baik pada hakim Ad-hoc maupun yang berada di Kepaniteraan Pengadilan Hubungan Industrial.

b. Pemerintah dan DPR perlu merubah UU No. 2 Tahun 2004 tentang penyelesaian Penyelesaian Hubungan Industrial (PHI) terutama Pasal 89 ayat (1) dan pasal 103. 
c. Lembaga non litigasi tidak berfungsi sebagailembaga alternatif ada baiknya sekalian untuk tidak membuang waktu, tidak ada penyelesaian di tingkat bipartit langsung saja mendaftarkan perselisihan ke $\mathrm{PHI}$, sehingga menghemat waktu 60 hari, yang berarti hanya membutuhkan waktu 80 hari untuk penyelesaian sampai putusan di Mahkamah Agung.

\section{DAFTAR PUSTAKA}

\section{Buku}

Guba dan Lincoln, Computing Paradigms in Qualitative Research, dalam Handbook of Qualitative Research, London, Sage Publikation, 1994, hlm. 105.

Karl A Slaikeu, When Push Comes to Shove: A Practical Strategies for Resolving Disputes (San Fransisco: Jossey-Bass Inc. 1996) hIm. 3.

Lilik Mulyadi dan Agus Subroto, Penyelesaian Perkara Pengadilan Hubungan Industrial dalam Teori dan Praktik, Penerbit Alumni, Bandung, 2011.

Norman K. Denzin, Yvonna S. Lincoln, Handbook of Qualitative Research, terjemah Dariyatno, dkk, Pustaka Pelajar, Yogyakarta, 2009.

PN Yogyakarta. Data Jumlah Perkara yang Masuk ke PHI pada Pengadilan Negeri Yogyakarta Tahun 2006-2014. Bagian Register Perkara pada Pengadilan Negeri Yogyakarta, Yogyakarta. 2015.

R. Setiawan, Aneka Masalah Hukum dart Hukum Acara Perdata, Alumni, Bandung, 1992,

Soemitro, Ronny Hanitijo. Metodologi Penelitian Hukum dan Jurimetri, Ghalia Indonesia, Jakarta. 1990.

Sunggono, Bambang. 2003, Metodologi Penelitian Hukum, PT Raja Grafindo Persada, Jakarta, 2003.

\section{Jurnal Penelitian/Majalah/Karya IImiah}

Kamus Besar Bahasa Indonesia. Balai Pustaka Jakarta, 1994.

Koentjaraningrat. Metode-Metode Penelitian Masyarakat, Gramdedia Pustaka Utama, Jakarta, 1997.

Gunarto. Rekonstruksi Konsep Kebebasan Berserikat Melalui Serikat Pekerja pada Hubungan Industrial Berbasis Nilai Keadilan Menuju Kesejahteraan Pekerja. Ringkasan Disertasi. Program Doktor IImu Hukum Universitas Diponegoro. 2011.

Uwiyono, Aloysius. Implikasi Hukum Pasar Bebas dalam Kerangka AFTA terhadap Hukum Ketenagakerjaan di Indonesia. Jurnal Hukum Bisnis, Vol. 22, Yayasan Pengembang Hukum Bisnis, Jakarta, 2003.

\section{Peraturan Perundang-undangan}

Undang-Undang Dasar Negara RI Tahun 1945

Undang-Undang Nomor 13 Tahun 2003 tentang Ketenagakerjaan.

Undang-Undang Nomor 2 Tahun 2004 tentang Penyelesaian Perselisihan Hubungan Industrial. Kitab Undang-Undang Hukum Perdata (BW)

Pasal 3 ayat (1) Undang-undang Nomor 2 Tahun 2004

Pasal 14 ayat (1) ayat (1) huruf h Undang-undang No. 32 Tahun 2004 tentang Pemerintahan Daerah.

UU Nomor 8 Tahun 2004 tentang Perubahan atas Undang-Undang Nomor 2 Tahun 1986 tentang Peradilan Umum.

Keputusan Presiden No. 1 Tahun 2005 tentang Penangguhan Mulai Berlakunya Undang-Undang No. 2 Tahun 2004. 